\title{
Practice patterns of obstetrician-gynecologists regarding preconception and prenatal screening for cystic fibrosis
}

Maria A. Morgan, $P h D^{1}$, Deborah A. Driscoll, $M D^{2}$, Michael T. Mennuti, $M D^{1,2}$, and Jay Schulkin, $P h D^{1}$

\begin{abstract}
Objective: To assess practices of obstetrician-gynecologists regarding carrier screening for cystic fibrosis (CF). Methods: A questionnaire investigating practice patterns and opinions pertaining to $\mathrm{CF}$ screening was mailed to 1165 members of the American College of Obstetricians and Gynecologists (ACOG), of whom 565 participate in the Collaborative Ambulatory Research Network (CARN) and 600 were randomly selected. Results: Of the questionnaires, $64 \%$ were returned. Statistical analyses were limited to the 632 respondents whose primary medical specialty was gynecology (Gyn Only) or obstetrics and gynecology (ObGyn). CARN membership was not a significant factor on any nondemographic measure. Almost one-half of physicians do not ask nonpregnant patients their family history of CF or provide them with information about CF screening. The majority of ObGyns (88.7\%) ask obstetric patients their family history of $\mathrm{CF}$, and offer CF carrier screening. Almost two-thirds (65.8\%) offer screening to all prenatal patients. Among those ObGyns who selectively offer CF screening to pregnant patients, only $27.4 \%$ utilized all of the selection criteria in the guidelines. Liability for not offering screening, familiarity with $\mathrm{CF}$, and the ability to interpret a positive screening test were important physician concerns. Conclusion: The results indicate a need for minimizing the complexity of clinical guidelines for population-based genetic screening, prospective assessment of implementation and focused continuing education for providers. Genet Med 2004:6(5):450-455.
\end{abstract}

Key Words: cystic fibrosis, carrier screening, prenatal, preconception, questionnaire

Screening for birth defects and certain genetic diseases has become a part of obstetric care. Maternal serum screening is broadly offered to assess the risks of neural tube defects and Down syndrome, and carrier screening for specific genetic diseases is offered to patients who are members of a high-risk ethnic group, e.g., Tay Sachs and Canavan disease in Eastern European Jewish population. Advances in genetics have resulted in the availability of carrier screening for many more genetic diseases and for predisposition to later onset diseases. Cystic fibrosis (CF) is the most common life-limiting autosomal recessive disease in Caucasians. Guidelines for carrier screening for $\mathrm{CF}$ in the preconception and prenatal care setting were developed by the American College of Medical Genetics, the American College of Obstetricians and Gynecologists, and NIH in response to a Consensus Development Panel report indicating that CF carrier screening should be offered to the following: couples with a family history of CF; couples in which one partner has CF; and couples planning a pregnancy, or seek-

\footnotetext{
From the ${ }^{1}$ American College of Obstetricians and Gynecologists, Washington, DC; and the ${ }^{2}$ Department of Obstetrics and Gynecology, University of Pennsylvania, Philadelphia, Pennsylvania.

Maria Morgan, American College of Obstetricians and Gynecologists, Research Department, 409 12th Street, SW, Washington, DC 20024.

Received: May 3, 2004.

Accepted: June 21, 2004.
}

DOI: 10.1097/01.GIM.0000139509.04177.4B ing prenatal testing. ${ }^{1}$ A multidisciplinary process was used to develop both clinical and laboratory guidelines for implementation. These were published and mailed to all ACOG members in October 2001.2 As the process for development and implementation of the guidelines might be used as a prototype for future recommendations and guidelines regarding genetic screening, it is important to evaluate the experience with CF screening not only in terms of the technical and laboratory aspects but also the implementation in clinical practice.

Although options to reduce or avoid the risk of having a child with CF are greater when screening is provided before conception, it has been observed that patient interest in CF screening is low before conception. ${ }^{3}$ Furthermore, relatively few patients seek preconception consultation and a large portion of pregnancies in the United States are unplanned or unintended. ${ }^{4}$ In contrast, studies have demonstrated greater uptake of screening during early pregnancy and successful implementation of screening. ${ }^{5-7}$ Reported increases in CF carrier screening test requests after publication of the guidelines provide only a very indirect measure of the implementation. The frequency of CF screening is dependent upon the frequency with which obstetrician-gynecologists and other health care providers offer this test to patients. In addition, the frequency of CF screening is dependent upon the frequency of preconception evaluation, gestational age at first prenatal visit and patient acceptance of the screening. There is little information regarding the extent to which obstetrician-gynecolo- 
gists have incorporated offering CF carrier screening tests into preconception or prenatal care. Furthermore there is little information regarding physician concerns about offering this screening test.

This survey was undertaken to increase our understanding of when, how, and in what populations obstetrician-gynecologists are implementing the published guidelines for CF carrier screening and to learn the physicians' opinions and practices regarding $\mathrm{CF}$ screening.

\section{MATERIALS AND METHODS}

Prevalidated and IRB-approved questionnaires were mailed in September 2003 to 1165 American College of Obstetricians and Gynecologists (ACOG) Fellows and Junior Fellows in Practice. Of these subjects, 565 were members of the Collaborative Ambulatory Research Network (CARN). Members of CARN are practicing obstetrician-gynecologists, both Fellows and Junior Fellows in Practice, who have volunteered to participate in survey studies on a regular basis. Volunteers are recruited through the use of an introductory letter periodically sent to a computer-generated random sample of ACOG members. CARN was established to facilitate assessment of clinical practice patterns and aid the development of educational materials. The remaining 600 subjects consisted of a computergenerated random sample of ACOG Fellows and Junior Fellows in Practice who are practicing obstetrics and/or gynecology and had not received a survey from ACOG during the previous two years (Non-CARN). All nonrespondents received a second mailing of the questionnaire five weeks after the first mailing. A final reminder mailing was sent approximately six weeks later. Questionnaires returned by January 9, 2004 were included in the survey. This protocol has typically resulted in a total sample size of $>450$, which is sufficient to detect differences between groups of $<0.5$ standard deviation with power of $80 \%$ and significance at the 0.05 level. ${ }^{8}$

The survey recorded demographic details of physicians and their patient population, as well as professional concerns and practices regarding CF screening in pregnant and nonpregnant patients. Questions assessing basic knowledge of CF, as well as professional training and experience regarding $\mathrm{CF}$ and screen- ing were also asked and will be addressed elsewhere. The majority of questions were of a multiple-choice format, and a multipart question asked physicians to rate their level of concern with several statements regarding CF screening.

The data were analyzed using a personal computer-based software package (SPSS 12.0, SPSS Inc., Chicago, IL). Descriptive statistics were computed for the measures used in the analyses, which are reported as mean \pm SEM. Student's $t$ test' was used to compare group means of age. Group differences of continuous measures were assessed using univariate analysis of variance with gender and residency-bins as fixed factors. Differences on categorical measures were assessed using $\chi^{2}$. Group differences on ordinal measures were assessed using the MannWhitney $U$ test. All analyses were tested for significance using an alpha of 0.05 .

\section{RESULTS}

A total of 753 questionnaires were returned. Data from 22 respondents were judged invalid (physician retired, returned to sender), resulting in a valid response rate of $64 \%(731 / 1143)$ : 419 from CARN members (75\% response rate) and 312 from Non-CARN (53.4\% response rate). Of these valid returns, 432 (59.1\%) were from men and 299 (40.9\%) were from women. Male respondents were significantly older than female respondents $[50.24 \pm 0.48$ versus $43.51 \pm 0.51 ; \mathrm{t}(729)=9.45 ; P<$ $0.001]$. Age and sex ratio closely matched the characteristics of the larger population to whom the survey was sent. There were responding physicians from every state of the United States, as well as the District of Columbia, Puerto Rico, Canada, and overseas military installations.

The remaining analyses will be limited to the $86.46 \%$ (632) of respondents who indicated that their primary medical specialty was gynecology or general obstetrics and gynecology. Both groups of physicians include nonpregnant patients of reproductive age in their practice, but ObGyns also see pregnant patients and Gyn Onlys do not (where both subject groups are combined, we typically refer to them as physicians). This subject selection was done in order to best assess the practices of nonsubspecialist obstetricians and gynecologists. Of these physicians, $13.5 \%(n=85)$ were Gyn Onlys, and $86.6 \%(n=$

Table 1

Physician demographics

\begin{tabular}{|c|c|c|c|c|c|}
\hline \multirow[b]{2}{*}{ Characteristics } & \multirow[b]{2}{*}{ Total $(N=632)$} & \multicolumn{2}{|c|}{ CARN } & \multicolumn{2}{|c|}{ Non-CARN } \\
\hline & & Male $(n=211)$ & Female $(n=155)$ & Male $(n=153)$ & Female $(n=113)$ \\
\hline Gender \% & M:57.6 F:42.4 & 57.7 & 42.3 & 57.5 & 42.5 \\
\hline Mean age $e^{a}$ & $47.12 \pm 0.39$ & $50.57 \pm 0.61$ & $44.44 \pm 0.62^{b}$ & $49.10 \pm 0.86$ & $41.69 \pm 0.90$ \\
\hline Mean yrs since residency ${ }^{a}$ & $15.38 \pm 0.38$ & $18.92 \pm 0.62$ & $12.43 \pm 0.59^{b}$ & $17.34 \pm 0.83$ & $10.14 \pm 0.85$ \\
\hline$\%$ See OB patients & 86.6 & 87.7 & 84.5 & 86.9 & 86.7 \\
\hline Mean deliveries 2002 & $136.23 \pm 3.68$ & $143.30 \pm 5.99$ & $139.19 \pm 9.63$ & $138.22 \pm 6.79$ & $116.41 \pm 6.68$ \\
\hline
\end{tabular}

${ }^{a} \mathrm{P}<0.001$ Males were older than females $[\mathrm{t}(630)=8.95]$ and had been out of residency longer $[\mathrm{t}(622)=9.42]$.

${ }^{b} \mathrm{P}<0.05$ CARN females were older than Non-CARN females $[\mathrm{t}(266)=2.58]$ and had been out of residency longer $[\mathrm{t}(263)=2.29]$. 
547) were ObGyns. 57.9\% of respondents were CARN members. See Table 1 for basic demographics. Physicians estimated that $63.53 \pm 1.04 \%$ of their patients were non-Hispanic white, $15.41 \pm 0.67 \%$ were African American, $13.57 \pm 0.75 \%$ were Hispanic, and $4.46 \pm 0.38 \%$ were Asian/Pacific Islander. Physicians were also asked to described their own ethnicity: $80.9 \%$ indicated non-Hispanic white, $6.7 \%$ Asian/Pacific Islander, 4.6\% Hispanic, and 3.6\% African American. Nondemographic data are collapsed across CARN and Non-CARN subjects, as the two groups did not differ on any measure analyzed.

\section{Practice patterns: Nonpregnant patients}

\section{Family history}

Physicians were asked several questions about the inclusion of questions regarding genetic diseases, and specifically about $\mathrm{CF}$, when taking a medical history of patients with reproductive potential who are not currently pregnant. Slightly less than one-half (48\%) of all the physicians routinely include questions to assess family and genetic history when taking a patient's medical history, whereas just over one third (35.2\%) does so only if the patient is attempting pregnancy. Fewer than one in seven physicians (13.5\%) always inquire about $\mathrm{CF}$ when taking a family history, though just over a third (36.4\%) asks about family history of CF if the patient is attempting pregnancy. Almost half (45.3\%) never specifically asks about family history of CF. ObGyns were more likely than Gyn Onlys to ask about family history of $\mathrm{CF}$ if the patient is attempting pregnancy $\left(38.4 \%\right.$ vs. $\left.23.5 \% ; \chi^{2}=8.57 ; P=0.036\right)$. Physicians who had completed their residency more recently ( $\leq 15.38$ years, the mean years since completion) were less likely than more experienced physicians ( $>15.38$ years since residency) to say they always ask about family history of CF (10.1\% vs. $17.2 \%)$ but are more likely to do so if the patient is attempting pregnancy $\left(42.6 \%\right.$ vs. $\left.29.6 \% ; \chi^{2}=12.48 ; P=0.002\right)$.

\section{Providing information about $C F$}

Slightly less than one-half (46.5\%) of the physicians said they do not routinely provide their patients with information regarding CF and CF screening; only $6.3 \%$ of physicians said they always provide information, and $38.4 \%$ said they do so if the patient is attempting pregnancy.

\section{Offering carrier screening}

When physicians were asked if they offer CF carrier screening to their nonpregnant patients, fewer than one in seven (13.1\%) physicians offer carrier screening to all nonpregnant patients, and almost one in five (19.2\%) never offer CF screening. The remaining $67.7 \%$ (417) of physicians selected one or more possible scenarios in which they offer carrier screening, with patient request the most frequently selected option, followed by a family history of $\mathrm{CF}$, and having a reproductive partner who has CF or is a known carrier. Only a quarter of the physicians selecting scenarios offered screening based on patient ethnicity, and only $18 \%$ selected the options that encompassed the criteria for offering screening in the published guidelines. See Table 2. ObGyns were less likely than Gyn Onlys to say they never offer CF carrier screening (17.3\% vs. $30.6 \% ; \chi^{2}=8.43 ; P=0.004$ ).

It is important to note here that this survey question was in a "check all that apply" format rather than a forced-choice/ yes-no format. As such, it should not be concluded, for example, that $20 \%$ of practitioners would refuse testing even if the patient requested it, but only that $80 \%$ indicated that they would offer testing if requested. It is quite possible that many physicians may not have checked the response option "Yes, if she requests it" because they have never had a nonpregnant patient request it, not because they would actually refuse such a request. Similarly, for those who do not check "If she has a family history of CF," it may be because they do not know if she has a family history of CF, not because they would not offer it in this higher-risk situation; such an explanation is quite probable, given that a very similar proportion $(\approx 45 \%)$ of physicians does not ask about a family history of CF.

\section{Practice patterns: Pregnant patients}

A similar set of questions was asked regarding screening practices with pregnant patients. Responses were limited to the $86.6 \%$ of physicians who are ObGyns and thus see pregnant patients. The vast majority of ObGyns (88.7\%) said they routinely ask their pregnant patients if she or her partner has a family history of CF, and $86.6 \%$ said they provide information regarding CF screening. Almost two thirds (65.8\%) of ObGyns said they offer carrier screening to all of their pregnant patients, and only $2.2 \%$ said they never offer CF carrier screening. The remaining $32 \%$ of ObGyns selected one or more of four possible situations in which they would offer screening. Of the $32 \%$, patient request was the most commonly selected response $(67.1 \%)$, followed by a family history of CF $(61.8 \%)$, partner has CF or is a known carrier (51.2\%), and patient ethnicity (46.7\%). Only $27.4 \%$ selected all of the options that encompassed the criteria in the published guidelines. See Table 3 , Pregnant Patients.

\section{Table 2}

Offer CF carrier screening to nonpregnant patients?

\begin{tabular}{lc}
\hline (check All, No, or all that apply of 4 situations) & $(n=632)$ \\
\hline Yes, offer screening to all patients & $\mathbf{1 3 . 1 \%}$ \\
Yes, offer screening in some situations: & $\mathbf{6 7 . 7 \%}$ \\
(check all that apply of situations 1-4) & $(n=417)$ \\
1. If she requests it & $80.1 \%$ \\
2. If she has a family history of CF & $54.7 \%$ \\
3. If her reproductive partner has CF or is carrier & $43.6 \%$ \\
4. If she or partner is higher-risk racial/ethnic & $25.2 \%$ \\
$\quad$ group & \\
Checked all 4: & $18.0 \%$ \\
No, I do not offer CF carrier screening & $\mathbf{1 9 . 2 \%}$ \\
\hline
\end{tabular}

Italicized values are percents of subjects within the "some situations" category, who checked one or more of options 1-4. 
Table 3

General ObGyns screening for CF in gynecologic and pregnant patients

\begin{tabular}{|c|c|c|}
\hline & Gynecological Patients & Pregnant Patients \\
\hline Yes, ask specifically if patient/partner has CF family history ${ }^{a}$ & $55.9 \%$ & $88.7 \%$ \\
\hline Yes, provide information regarding CF and CF screening ${ }^{a}$ & $54.7 \%$ & $86.6 \%$ \\
\hline \multicolumn{3}{|l|}{ Offer CF carrier screening to patients? } \\
\hline Yes, offer screening to all patients & $13.1 \%$ & $65.8 \%$ \\
\hline Yes, offer screening in some situations: & $69.6 \%$ & $32.0 \%$ \\
\hline (check all that apply of situations $1-4$ ) & $(n=370)$ & $(n=170)$ \\
\hline 1. If she requests it & $81.1 \%$ & $67.1 \%$ \\
\hline 2. If she has a family history of $C F$ & $54.3 \%$ & $61.8 \%$ \\
\hline 3. If her reproductive partner has CF or is carrier & $44.3 \%$ & $51.2 \%$ \\
\hline 4. If she or partner is higher-risk racial/ethnic group & $25.9 \%$ & $46.7 \%$ \\
\hline Checked all 4 & $18.1 \%$ & $27.4 \%$ \\
\hline No, I do not offer CF carrier screening & $17.3 \%$ & $2.2 \%$ \\
\hline
\end{tabular}

Italicized values are percents of subjects within the "some situations" category, who checked one or more of options 1-4.

a"Yes" for gynecological patients is the sum of any yes situation (e.g., always, only if attempting pregnancy).

Because the stage of gestation at the time of first visit may influence the rate at which ObGyns offer CF screening, we asked for an estimate of the percentage of patients in their practice who have a prenatal visit before 16 weeks gestation. ObGyns estimated that more than one in ten $(11.36 \pm 0.56 \%$; median $=8 \%)$ of their prenatal patients start prenatal care after 16 weeks of pregnancy

Almost two thirds (64.3\%) of ObGyns said they would offer to screen the patient's reproductive partner when confronted with a positive CF screening result in their pregnant patient, and the other third (35.3\%) said they would refer her to a genetic counselor/program. Just over a third $(37.2 \%)$ of ObGyns who responded personally perform amniocentesis. Of those who do not, $87.8 \%$ said that such services could be obtained on-site or within the community. Neither years since residency nor tendency to offer screening differed between those who performed amniocentesis and those who did not.

ObGyns' screening practices with nonpregnant patients were compared to their practices with pregnant patients. ObGyns were more likely to ask a pregnant patient than a gynecological patient about a family history of CF, provide information about $\mathrm{CF}$, and to offer screening to all patients. See Table 3.

\section{Opinions about screening}

ObGyns were asked to rate on a 5-point scale how much of a concern $(1=$ not a concern to $5=$ a big concern $)$ they thought several issues were to physicians regarding carrier screening. Over three quarters (77.2\%) of ObGyns rated liability from not offering screening as more than a moderate concern. Over one-half rated physician's confidence in their ability to interpret or deal with a positive screening test and physician's familiarity with genetics/CF as more than a moderate concern (see Table 4). Unreimbursed time spent on patient education

\section{Table 4}

Percent of ObGyns who rated the following factors as more than a Moderate Concern ( $4-5$ on a scale of $1=$ Not a Concern to $5=$ A Big Concern) to the average physician regarding $\mathrm{CF}$ carrier screening

\begin{tabular}{lc}
\hline & A Concern \\
\hline $\begin{array}{l}\text { Liability from not offering screening, if the patient } \\
\text { has a child with CF }\end{array}$ & $77.2^{a}$ \\
$\begin{array}{l}\text { Physician's confidence in their ability to interpret or } \\
\text { deal with a positive screening test }\end{array}$ & $59.5^{b}$ \\
$\begin{array}{l}\text { Physician's level of familiarity with genetics and } \\
\text { with CF }\end{array}$ & 58.9 \\
$\begin{array}{l}\text { Low frequency of CF compared to other important } \\
\text { obstetrical problems }\end{array}$ & 48.1 \\
$\begin{array}{l}\text { Unreimbursed time spent on patient education for } \\
\quad \text { CF screening }\end{array}$ & 39.3 \\
Rationale for screening for a chronic disease & 37.2 \\
\hline
\end{tabular}

${ }^{a} \mathrm{P}=0.003,{ }^{b} \mathrm{P}=0.042$ : ObGyns who had been in residency longer rated both items as more of a concern than less experienced residents.

for $\mathrm{CF}$ screening and the rationale for screening for a chronic disease received the lowest concern ratings.

On this set of issues, years since completing residency was a significant factor in both liability and test interpretation. ObGyns who had been in practice longer than 15.38 years rated both liability and test interpretation as more of a concern than did less experienced physicians.

\section{DISCUSSION}

Offering CF screening in the reproductive health care setting was debated ever since the $\Delta F 508$ mutation was identified. The prospect of population screening for CF presented a number of complex issues. The selection of mutations to include in a screening panel, the sensitivity of testing in various racial and 
ethnic groups and the limitations inherent in applying information regarding mutations identified in a population with the disease to the general population has been extensively considered and reviewed. ${ }^{1,2,9,10}$ In addition, there were a number of concerns regarding how physicians might implement these recommendations, how patients would accept screening for a chronic disease with variable severity, and whether sufficient genetic services would be available to deal with patients needing counseling., ${ }^{9,11,12}$ Our survey, two years after ACOG/ ACMG issued the guidelines for CF carrier screening, attempted to explore some of these issues.

We were interested in the implementation of CF screening in the care of gynecological patients because experience in the clinical research setting indicated that patient interest in CF screening was low before conception. ${ }^{3}$ Barriers identified in other studies include problems reaching the patients, limited public knowledge of $\mathrm{CF}$, and absence of preconception genetic counseling settings. ${ }^{13}$ Close to half of couples invited to participate in a preconception CF carrier screening program failed to respond due to disinterest or lack of time. ${ }^{14}$ Patients who participated were satisfied with screening but none of the carriers changed their reproductive plans. ${ }^{15}$ It is also possible that physicians may not be fully aware or may not convey information regarding options available to carrier couples such as donor gametes, or preimplantation genetic diagnosis.

Despite this experience it was recommended that screening should be offered to couples planning a pregnancy because preconception screening affords patients the widest range of options to avoid or reduce the risk of having a child with CF. This was described as couples seeking preconception evaluation or fertility care. ${ }^{2}$ It is reasonable to expect less implementation and lower uptake of CF screening in gynecologic practice. Of concern is that $30.6 \%$ of Gyn Onlys never offer screening. It is possible that some portion of this group deals primarily with patients beyond the reproductive age. However, it is likely that the majority care for some patients who may become pregnant in the future. It should also be noted that the majority of Gyn Onlys who offer screening use selective criteria and only a low percentage offer CF screening to all patients (13.1\%). Not unexpectedly, patient request was the most frequently selected reason for offering screening. Selection based on all of the criteria described in the guidelines were only uniformly applied by $18 \%$ of the Gyn Onlys. Of note, ObGyns, who are more likely to offer screening to prenatal patients, were also found to more frequently ask about family history and to offer screening in the gynecologic practice setting, particularly to those patients who express interest in becoming pregnant.

The vast majority of ObGyns ask their pregnant patients about a family history of $\mathrm{CF}$ and provide information about $\mathrm{CF}$ carrier screening to their patients. Although a significant number of ObGyns indicated more than moderate concern over their ability to interpret a positive result, this does not appear to deter them from offering CF screening. This high frequency of offering screening during pregnancy may reflect a combination of their heightened concern for a healthy outcome once a pregnancy is confirmed, use of prenatal medical record forms that prompt them to inquire about family history of specific genetic disorders, familiarity with carrier screening for other genetic disorders in specific ethnic populations, or greater patient interest in screening during pregnancy.

Notably, the majority of ObGyns are not identifying pregnant patients at risk for having a child with CF based on ethnicity and race and two-thirds of ObGyns offer CF screening to all of their pregnant patients. Of the third who use the selective criteria, only $46.7 \%$ selected ethnicity as an indication to offer screening, and the majority failed to select all of the recommended criteria for offering screening. There are several possible explanations for this practice. Of most concern is that the criteria for offering screening may be confusing or too complex. The guidelines distinguish between "offering" screening and "making it available." The latter designation encompasses those patients who do not have CF or a history of CF, and are in an ethnic/racial group that has a relatively low risk of having a child with CF and in whom the test is less sensitive. In these patients, "making it available" requires that the patient request the test, but after the physician has provided her with adequate educational materials to make an informed decision. Physicians may also have difficulty assigning a patient to a particular ethnic group or they may simply find it more practical to offer screening to all patients. As the majority of all ObGyns (77.2\%) rated liability from not offering carrier screening as one of the major concerns regarding CF screening, it is also possible that the practice of offering testing to all pregnant patients relates to concern about potential liability for not offering screening to a patient who may subsequently have a child with CF irrespective of the level of risk or the sensitivity of screening in her racial or ethnic group.

ObGyns estimated that the majority of their patients present for prenatal care before 16 weeks gestation so it is unlikely that this substantially affects the rate of offering screening. Over $50 \%$ of ObGyns indicated that they are moderately concerned about their ability to interpret a positive result and feel unfamiliar with genetics and CF. This was increased among ObGyns who are more remote from training. Nevertheless, based on their responses it appears that the follow-up of patients with a positive screening test is appropriate. The majority of ObGyns offer to screen the partner when the patient is identified as a carrier of a CF mutation, whereas one-third refer to a genetic counselor or genetics program. Prenatal diagnosis is either available with the ObGyn or at a genetic program on site or nearby. Access to genetic services, a concern before the development of the guidelines, does not appear to be a limiting factor.

It is reasonable to expect that the publication of new guidelines will require some period of time to be incorporated in practice. Furthermore, experience in clinical practice may guide revisions of guidelines or development of additional educational materials for providers or patients. Such efforts might result in improved implementation. The results of our survey indicate that the ACOG/ACMG clinical and laboratory guidelines have substantially altered practice during the first 
two years after they were published. The low frequency of offering CF screening in gynecological practice may point to the need for additional education of physicians regarding circumstances in which this would be appropriate. It is also possible that the lack of interest in preconception screening among patients is driving physician practice. We believe that further consideration should be given to the issues surrounding preconception CF carrier screening and that either revision and/or focused education should be considered. In contrast, the vast majority of ObGyns have incorporated CF carrier screening into their obstetric practice. However, many are unaware of selection criteria for offering screening and have adopted an approach of offering screening to all patients. We believe that this suggests that complexity of future guidelines for genetic screening should be minimized. Similarly, concerns of the ObGyns about their lack of familiarity with genetics and CF suggest a need for focused continuing education.

\section{ACKNOWLEDGMENTS}

This work was supported in part by a grant from the HRSA$\mathrm{MCHB}$ and the CDC.

\section{References}

1. NIH Consensus Development Conference Statement. Genetic testing for cystic fibrosis. April 14-16, 1997. Arch Int Med 199;159:1529-1539.

2. American College of Obstetricians and Gynecologists, and American College of Medical Genetics. Preconception and prenatal carrier screening for cystic fibrosis. Clinical and laboratory guidelines. American College Obstetricians and Gynecologists, Washington, DC, 2001.
3. Clayton EW, Hannig VH, Pfotenhauer JP, Parker RA, Campbell PW III, Phillips JA III. Lack of interest by nonpregnant couples in population-based cystic fibrosis carrier screening. Am J Hum Genet 1996;58:617-627.

4. AGI-Alan Guttmacher Institute. Sex and America's Teenager. New York: Alan Guttmacher Institute, 1994.

5. Loader S, Caldwell P, Kozyra A, Levenkron JC, Boehm CD, Kazazian HH Jr et al. Cystic fibrosis carrier population screening in the primary care setting. Am J Hum Genet 1996;59:234-247.

6. Levenkron JC, Loader S, Rowley PT. Carrier screening for cystic fibrosis: test acceptance and one year follow-up. Am J Med Genet 1997;73:378-86.

7. Witt DR, Schaefer C, Hallam P, Wi S, Blumberg B, Fishbach A et al. Cystic fibrosis heterozygote screening in 5,161 pregnant women. Am J Hum Genet 1996;58:823835.

8. Power ML, Holzman GB, Schulkin J. Obstetrician-gynecologists' views on the health risks of obesity. J Repro Med 2001;46:941-946.

9. Mennuti MT, Thomson E, Press N. Screening for cystic fibrosis: Follow-up workshop to the NIH consensus development conference. Obstet Gynecol 1999;93:456461.

10. Grody WW, Cutting GR, Klinger KW, Richards CS, Watson MS, Desnick RJ. Laboratory standards and guidelines for population-based cystic fibrosis carrier screening. Genet Med 2001;3:149-154.

11. Haddow JE, Bradley LA, Palomaki GE, Doherty RA, Bernhardt BA, Brock DJ et al. Issues in implementing prenatal screening for cystic fibrosis: results of a working conference. Genet Med 1999;1:129-35.

12. Watson MS, Grody WW, Mennuti MT, Popovich BW, Richards CS. Cystic fibrosis carrier screening: issues in implementation. Genet Med 2003;4:407-409.

13. Poppelaars FA, van der Wal G, Braspenning JC, Cornel MC, Henneman L, Langendam MW et al. Possibilities and barriers in the implementation of a preconceptional screening programe for cystic fibrosis carriers: a focus group study. Public Health 2003;117:396-403.

14. Henneman L, Bramsen I, van Kempen L, van Acker MB, Pals G, van der Horst HE et al. Offering preconceptional cystic fibrosis carrier couple screening in the absence of established preconceptional care services. Comm Genet 2003;6:5-13.

15. Henneman L, Bramsen I, van der Ploeg, ten Kate LP. Preconception cystic fibrosis carrier couple screening: impact, understanding, and satisfaction. Genet Test 2002; 6:195-202. 